\title{
Identification and Characterization of a Luteinizing Hormone Receptor (LHR) Homolog from the Chinese Mitten Crab Eriocheir sinensis
}

\author{
Li-Juan Yuan ${ }^{1,2,3,4,+}$, Chao Peng ${ }^{1,2,3,4,+}$, Bi-Hai Liu 1,2,3,4 , Jiang-Bin Feng ${ }^{1,2,3,4}$ and \\ Gao-Feng Qiu 1,2,3,4,* \\ 1 National Demonstration Center for Experimental Fisheries Science Education, Shanghai Ocean University, \\ Shanghai 201306, China; m130111281@st.shou.edu.cn (L.-J.Y.); 15602258587@163.com (C.P.); \\ m170100139@st.shou.edu.cn (B.-H.L.); jbfeng@shou.edu.cn (J.-B.F.) \\ 2 Key Laboratory of Exploration and Utilization of Aquatic Genetic Resources, Ministry of Education, \\ Shanghai Ocean University, Shanghai 201306, China \\ 3 Key Laboratory of Freshwater Aquatic Genetic Resources, Ministry of Agriculture, Shanghai Ocean \\ University, Shanghai 201306, China \\ 4 Shanghai Engineering Research Center of Aquaculture, Shanghai Ocean University, Shanghai 201306, China \\ * Correspondence: gfqiu@shou.edu.cn; Tel./Fax: +86-21-61900436 \\ + These authors contributed equally to this work.
}

Received: 6 March 2019; Accepted: 4 April 2019; Published: 8 April 2019

\begin{abstract}
Luteinizing hormone (LH), a pituitary gonadotropin, coupled with LH receptor (LHR) is essential for the regulation of the gonadal maturation in vertebrates. Although LH homolog has been detected by immunocytochemical analysis, and its possible role in ovarian maturation was revealed in decapod crustacean, so far there is no molecular evidence for the existence of LHR. In this study, we cloned a novel LHR homolog (named EsLHR) from the Chinese mitten crab Eriocheir sinensis. The complete sequence of the EsLHR cDNA was 2775bp, encoding a protein of 924 amino acids, sharing $71 \%$ amino acids identity with the ant Zootermopsis nevadensis LHR. EsLHR expression was found to be high in the ovary, while low in testis, gill, brain, and heart, and no expression in the thoracic ganglion, eye stalk, muscle, and hepatopancreas. Quantitative PCR revealed that the expression level of EsLHR mRNA was significantly higher in the ovaries in previtellogenic (Pvt), late vitellogenic (Lvt), and germinal vesicle breakdown (GVBD) stages than that in the vitellogenic (Mvt) and early vitellogenic (Evt) stages $(P<0.05)$, and, the highest and the lowest expression were in Lvt, and Evt, respectively. The strong signal was mainly localized in the ooplasm of Pvt oocyte as detected by in situ hybridization. The crab GnRH homolog can significantly induce the expression of EsLHR mRNA at 36 hours post injection in vivo $(P<0.01)$, suggesting that $E s L H R$ may be involved in regulating ovarian development through GnRH signaling pathway in the mitten crab.
\end{abstract}

Keywords: luteinizing hormone receptor; expression profile; ovarian development; Eriocheir sinensis

\section{Introduction}

Luteinizing hormone (LH), a glycoprotein hormone secreted from the pituitary gland, is one of the main factors inducing oocyte maturation and ovulation in vertebrates [1]. Similar with follicle-stimulating hormone (FSH), the release of LH was regulated by gonadotropin-releasing hormone (GnRH) in the hypothalamic-pituitary-gonadal axis (HPG axis) [2]. LH works in coordination with $\mathrm{FSH}$, to induce gonads to synthesize and secrete maturation-inducing hormone (MIH), by combining its specific membrane receptor, LH receptor (LHR). Finally, MIH promotes proliferation of granulosa cell and maturation of germ cell [3]. 
LHR belongs to the rhodopsin-like G-protein coupled receptor (GPCR) family [4], the largest family of cell-surface receptors [5]. The GPCR family has undergone a long evolutionary history and exacts various biological functions, including animal reproduction [6]. LHR contains a typical structure of GPCR family members with an N-terminal extracellular domain (ECD), a seven transmembrane domain (TMD) and an intracellular domain (ICD) $[7,8]$. The ECD domain was rich in leucine-rich repeats (LRRs) and contained a highly conserved region of cysteine, which was involved in the hormone-binding process, while the TMD was responsible for signal transduction and G-protein coupling function $[9,10]$.

Due to the important role in the regulation of reproduction, $L H R$ has been characterized in a wide variety of vertebrate species, since it was first isolated from human placenta in 1997. In aquaculture species, the expression pattern and function of $L H R$ have been examined in many teleost species including Danio rerio [11], Dicentrarchus labrax [12], Acanthopagrus schlegeli [13], Hippoglossus hippoglossus [14], Oncorhynchus rhodurus [15], Salmo salar [16], Gadus morhua [17], Anguilla japonica [18], Clarias gariepinus [19], etc. LHR was primarily expressed in gonads. Additionally, LHR exhibited a high expression in head kidney $[19,20]$ and was detectable in other tissues of some fishes [19]. In the gonads, the expression level of the LHR exhibits obviously seasonal (reproductive stage-specific) rhythms. Expression of channel catfish (Letalurus Punetaus) LHR remained rather low at most stages in the reproductive cycle, but was significantly upregulated around the time of spawning [20]. In D. rerio, the expression of $L H R$ increased along with ovarian development and reached peak level at the full-grown oocyte stage [11]. In decapod crustacean, although LH protein has been detected by immunohistochemical analysis and has implication in ovarian maturation, there is no molecular evidence for the existence of LHR so far. In our previous study, high-throughput next-generation sequencing data analysis of the brain and ovary transcriptomes revealed a putative GnRH signaling pathway in the prawn Macrobrachium nipponense [5] and the Chinese mitten crab Eriocheir sinensis [21]. Like vertebrates, the expression of the GnRHR homologs has implications in ovarian development of prawns and crabs [5,22]. Therefore, we deduced that LHR could also exist in prawns and crabs, and function as a downstream factor in GnRH pathway in ovarian maturation. To test this hypothesis, in the present investigation we cloned and characterized the mitten crab E. sinensis LHR homolog transcript (EsLHR). We then examined its tissue distributions and spatial-temporal expression profiles during ovarian development, using quantitative PCR (qPCR) and in situ hybridization (ISH) analysis. We also examined the effect of the crab GnRH homolog on EsLHR expression in the ovarian development. The results could help us better understand the molecular mechanism of ovarian maturation and provide useful basic knowledge for the improvement of reproductive manipulation of crabs.

\section{Results}

\subsection{Molecular Characterization and Phylogenetic Analysis of EsLHR Homolog}

Based on a partial annotated sequence from the ovarian transcriptome library of the E. sinensis, the full-length cDNA sequence of the EsLHR was amplified by RACE-PCR from the ovary in E. sinensis and deposited in GenBank with accession number MK312165. The EsLHR cDNA was 2775 bp in length, encoding a putative peptide of 924 amino acids (aa). The $3^{\prime}$-untranslated region ( $3^{\prime}$-UTR) of the EsLHR has a potential polyadenosine with a base sequence of ATTAAA (Figure 1). Like other species, LHR, the deduced EsLHR possess typical features of glycoprotein receptors: N-terminal extracellular domain (ECD), seven transmembrane helix domain (TMD) and C-terminal intracellular domain (ICD), and a highly cysteine-rich region in the glycoprotein hormone receptor family: ERW, FTD and NPFLY (Figure 1). Seven exons were found in EsLHR gene after blasted in the genomic dataset of E. sinensis (unpublished data). Seven-TMD was encoded by the $3^{\text {th }}, 4^{\text {th }}, 5^{\text {th }}$, and $6^{\text {th }}$ exons of EsLHR gene (Figure 2). The multiple alignment of the deduced amino-acid sequences of EsLHR, with known LHRs from other species showed that EsLHR shares $52-71 \%$ identity with LHR sequences from other species. The highest amino acids identity (71\%) was found with the ant Zootermopsis 
nevadensis LHR. To assess the EsLHR protein and its evolutionary relationship, a phylogenetic tree was constructed using the NJ method. The dendrogram shown in Figure 3 depicts the evolutionary relationships based on the sequence similarity of EsLHR proteins from various species. The LHR and FSHR were separated into two clades. EsLHR protein was clustered together with the LHR from the horseshoe crab Limulus polyphemus and the scorpion Centruroides sculpturatus, indicating that the EsLHR belongs to LHR family rather than FSHR (Figure 3).

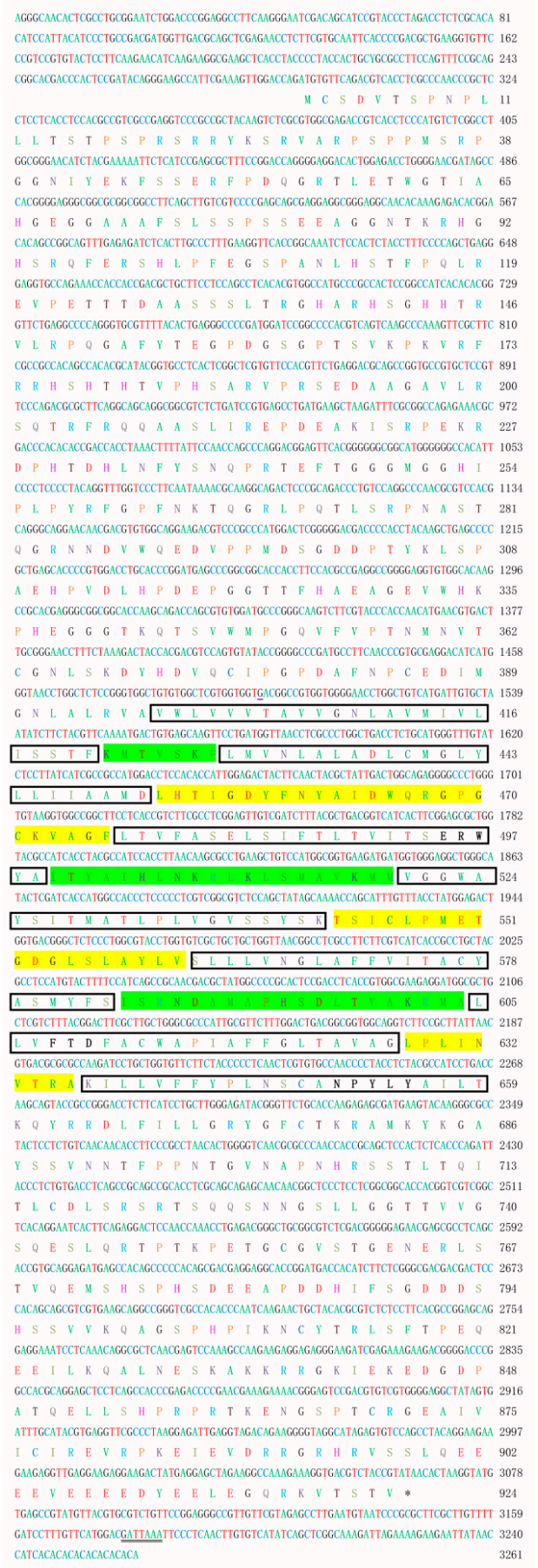

Figure 1. Molecular characteristics of EsLHR cDNA and its deduced peptide. The box indicates seven transmembrane helix regions; the green and yellow shadow highlight the intracellular, and the extracellular loop, respectively; the black font represent the special conserved signal sequence of G-protein coupled receptor (GPCR) family; the double underlined ATTAAA indicates a potential polyadenylation signal; the star marks the stop codon. 


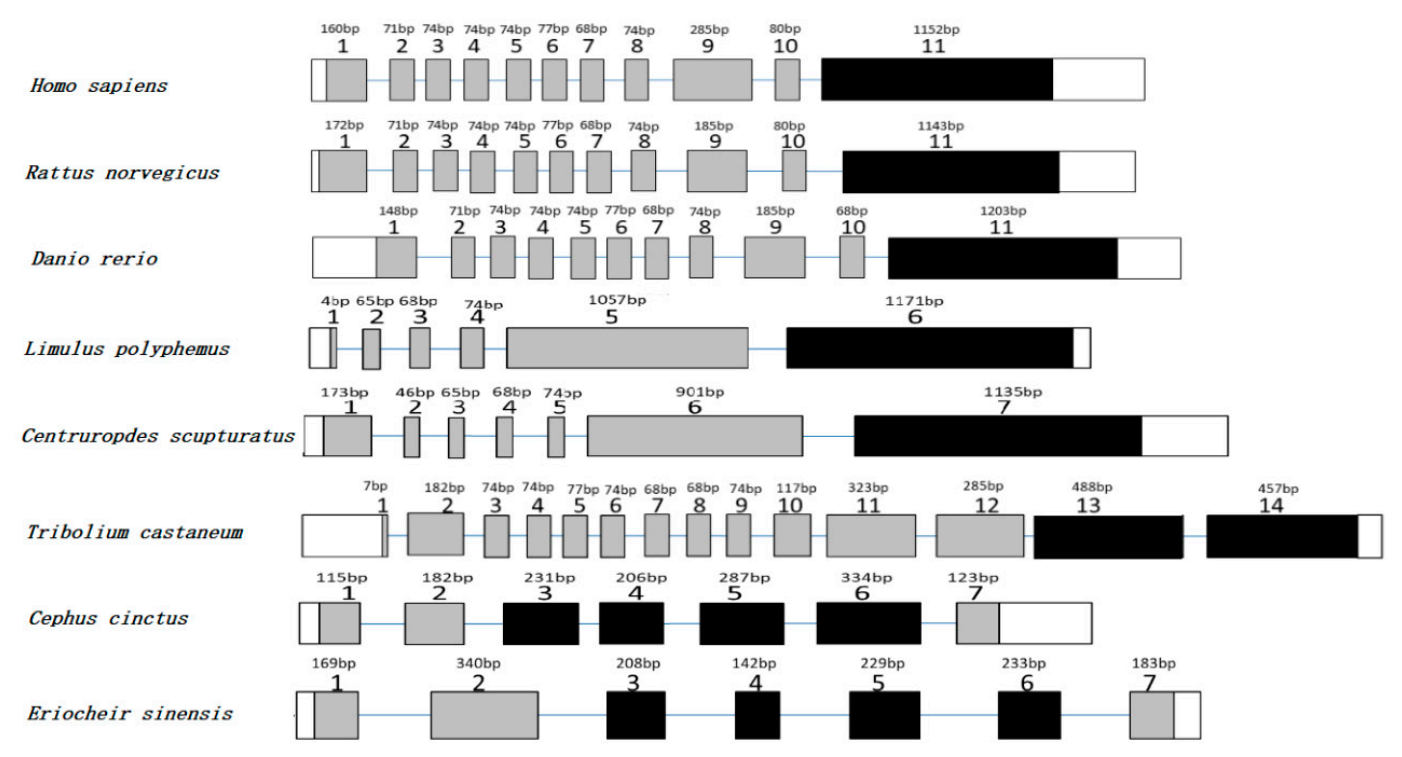

Figure 2. Schematic diagram of EsLHR gene structure as compared with various species. The gray and black boxes represent exons, in which the black indicates the exons coding the seven-transmembrane domain. Arabic numerals mark the exon positions. The length of each exon was indicated as base pairs (bp).

\subsection{Tissue Distribution of EsLHR $m R N A$}

The distribution of EsLHR mRNA in brain, ovary, testis, thoracic ganglion, eye stalk, heart, muscle, and hepatopancreas was determined by RT-PCR. As shown in Figure 4, the expression was the highest in the ovary, lower in testis and gill, brain and heart, whereas no expression in the thoracic ganglion, eye stalk, muscle and hepatopancreas. The result indicated that EsLHR is transcribed in a tissue-specific manner and may be involve in gonad development.

\subsection{ISH localization of EsLHR mRNA in the Ovaries at Various Stages}

Based on the ovarian tissue section observation, crab ovarian development can be classified into previtellogenic (Pvt), early vitellogenic (Evt), vitellogenic (Mvt), late vitellogenic (Lvt), and germinal vesicle breakdown (GVBD) stages. In Pvt, the nucleus of the oocyte was transparent and was termed germinal vesicle (GV), while the ooplasm and nucleolus were notably stained to a dark blue color by hematoxylin (Figure 5A). As appearance of in yolk protein, the ooplasm was stained to red by eosin at Evt, Mvt, Lvt, and GVBD stages (Figure 5D,G,J,M). The ISH results revealed that a strong positive signal was mainly visualized in the ooplasm of Pvt oocytes (Figure 5B). Subsequently, the signal became weaker and weaker as the oocytes grew larger and larger from Evt to Lvt stages (Figure 5E,H,K), and disappeared in the GVBD-oocyte at final maturation stage (Figure $5 \mathrm{~N}$ ). No hybridization signal was detected at any stages of ovarian development when a sense probe was used (Figure 5C,F,I,L,O). 


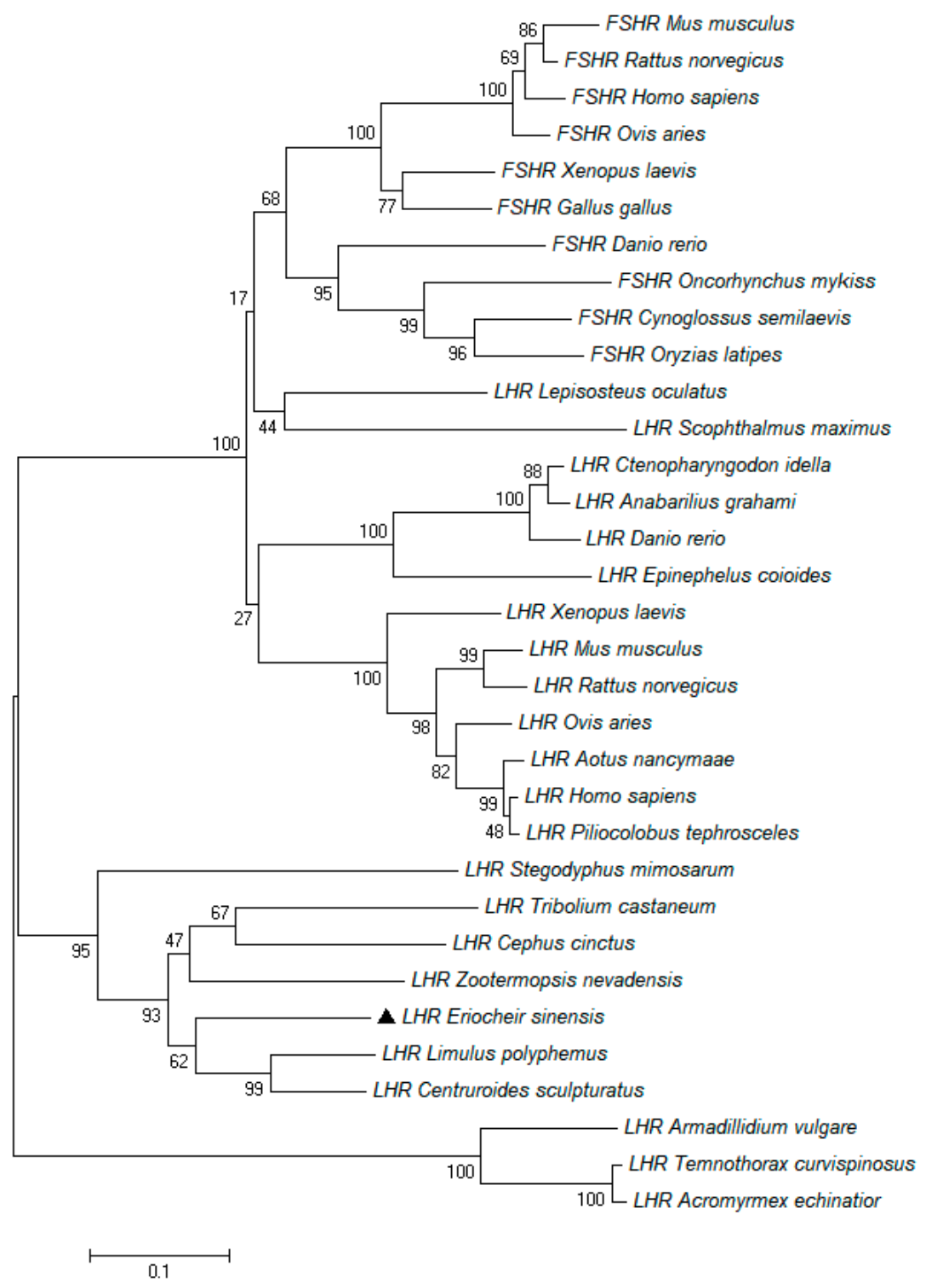

Figure 3. The neighbor-joining phylogenetic tree of EsLHR, and other known G-protein coupled receptor members; alignment of amino acid sequences are produced by Clustal $X$ and MEGA 6.0. The confidence in each node is assessed by 1000 bootstrap replicate. GeneBank accession numbers of above various species: Lepisosteus oculatus LHR (XP_015218187.1); Scophthalmus maximus LHR (AIE47234.1); Anabarilius graham LHR (ROL48811.1); Aotus nancymaae LHR (XP_012320900.1); Pilicolobus tephrosceles LHR (XP_023079591.2); Nephila clavipes LHR (PRD27275.1); Stegodyphus mimosarum LHR (KFM82218.1); Armadillidium vulgare LHR (RXG67696.1); Temnothorax curvispinosus LHR (XP_024869715.1); Acromyrmex echinatior LHR (EGI67461.1); Xenopus laevis LHR (BAL15689.1); Homo sapiens LHR (CAA59234.1); Ovis aries LHR (NP_001265495.1); Mus musculus LHR (EDL38653.1); Rattus norvegicus LHR (NP_037110); Danio rerio LHR (AAP33512.1); Ctenopharyngodon idella LHR (ABM73668.1); Oncorhynchus mykiss LHR (ACD39387.2); Epinephelus coioides LHR (AEG65827.1); Tribolium castaneum isoform LHR (XP_008195299.1); Limulus polyphemus LHR (XP_013780200.1); Centruroides sculpturatus LHR (XP_023235072.1); Cephus cinctus LHR (XP_024939991.1); Zootermopsis nevadensis LHR (KDR08863.1); Mus musculus FSHR (EDL38653.1); Rattus norvegicus FSHR (EDM02615.1); Homo sapiens FSHR (AAI25271.1); Ovis aries FSHR (XP_014949269); Xenopus laevis FSHR (BAL15688.1); Gallus gallus FSHR (NP_990410); Danio rerio FSHR (AAP33512.1); Oncorhynchus mykiss FSHR (AAQ04551.1); Orzias latipes FSHR (BAJ05402.1); Cynoglossus semilaevis FSHR (ACD39387.2). 


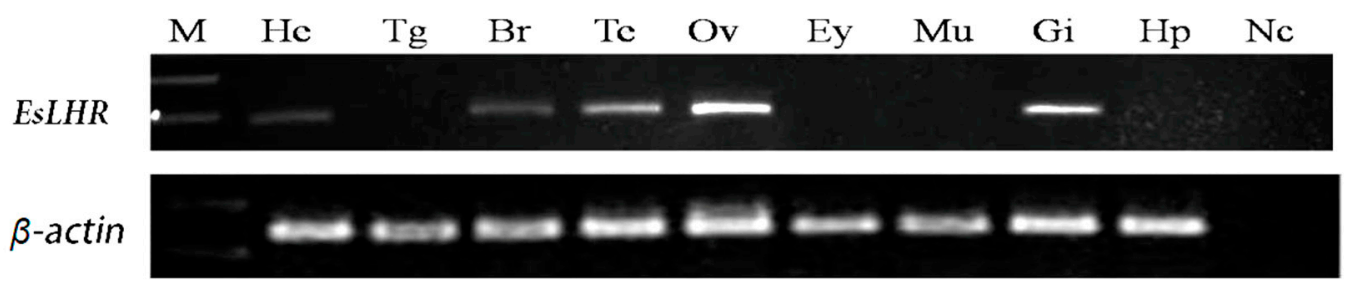

Figure 4. RT-PCR analysis of distribution of EsLHR mRNA in different tissues. M: marker; He: heart; Tg: thoracic ganglion; Br: brain; Te: testis; Ov: ovary; Ey: eye stalk; Mu: muscle; Gi: gill; Hp: hepatopancreas; Nc: negative control.

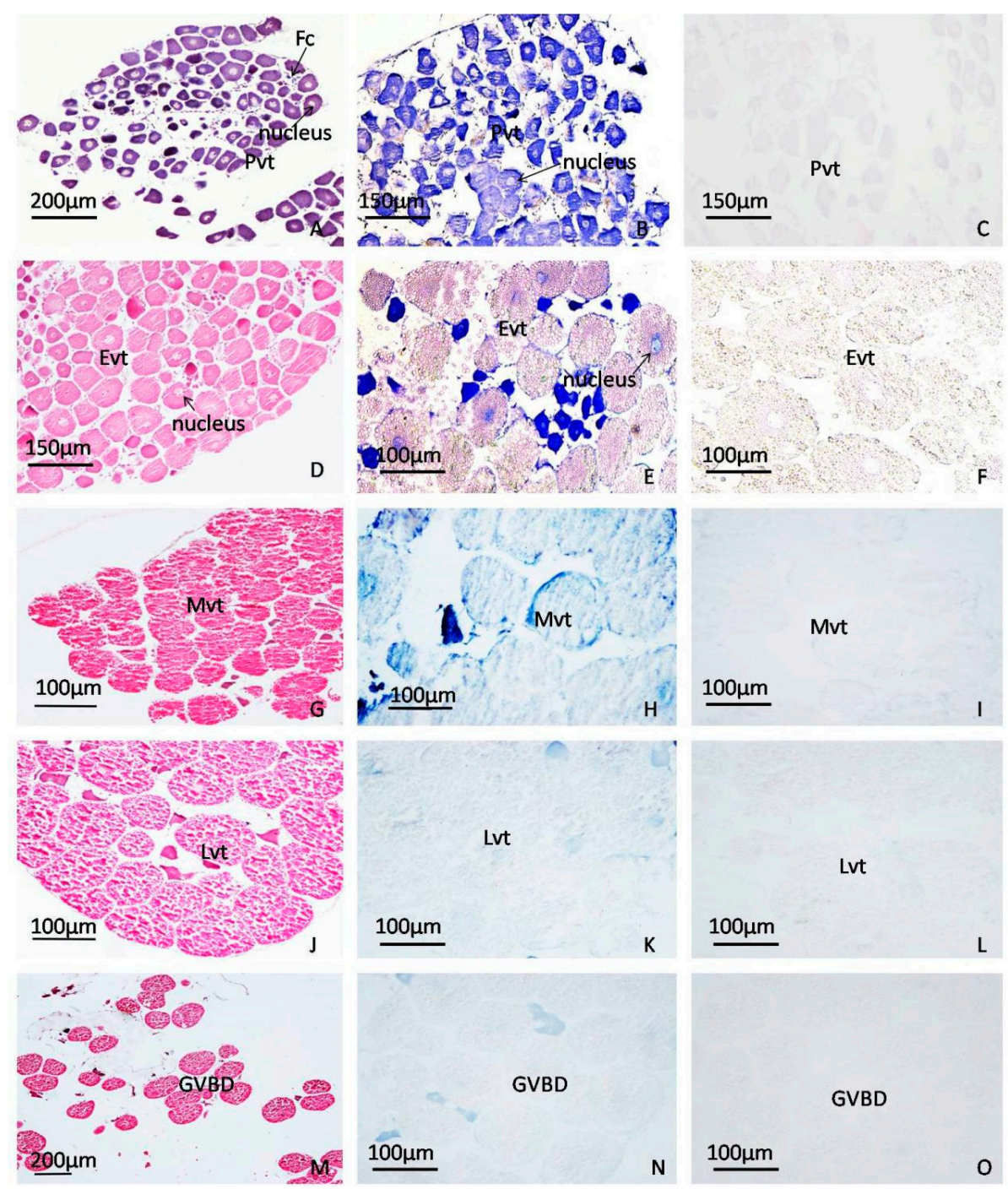

Figure 5. In situ hybridization (ISH) localization of EsLHR mRNA in the ovaries at various stages. (A-C), previtellogenic stage (Pvt); (D-F), early vitellogenic stage (Evt); (G-I), middle vitellogenic stage (Mvt); (J-L), late vitellogenic stage (Lvt); (M-O), germinal vesicle breakdown stage (GVBD). A, D, G, J, and M, HE staining; B, E, H, K, and N, ISH using antisense probes; C, F, I, L, and O, negative control using sense probes.

\section{4. qPCR Quantitation of EsLHR mRNA in the Ovaries at Various Stages}

To investigate the potential role of EsLHR in ovarian maturation, the expression level of EsLHR transcripts in the ovaries, at various stages, was quantified by qPCR analysis. As shown in Figure 6, the relative expression level of EsLHR mRNA in Pvt, Lvt, and GVBD stages were significantly higher 
than that of Mvt and Evt stages $(P<0.05)$. The highest and the lowest expression were found in Lvt, and Evt, respectively (Figure 6).

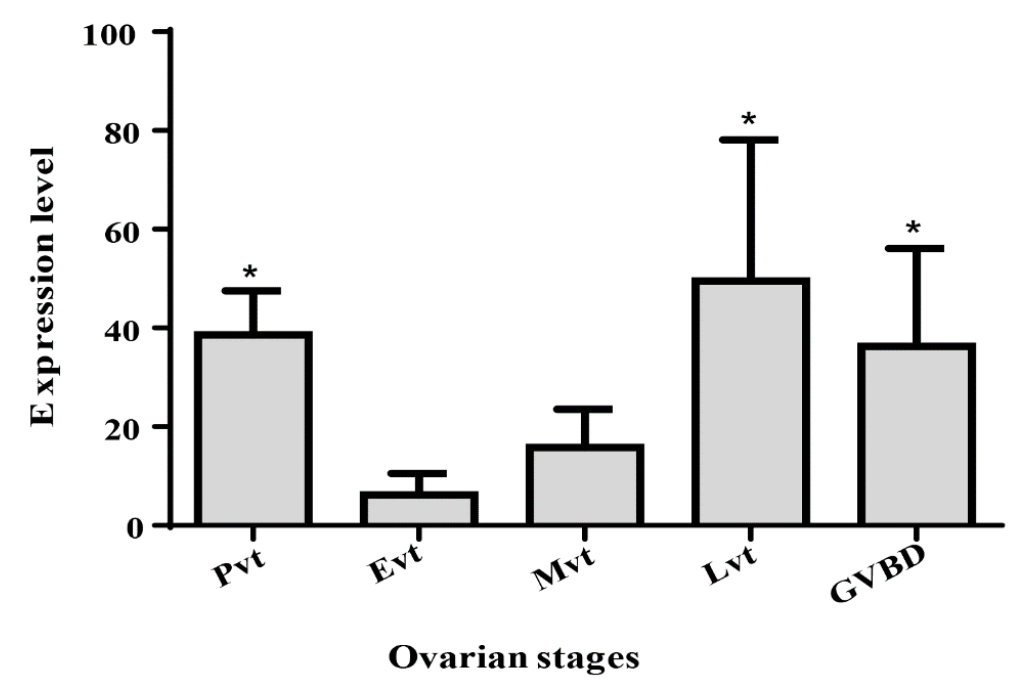

Figure 6. qPCR quantitation of EsLHR mRNA expression in the ovaries at various stages. Pvt, previtellogenic stage; Evt, early vitellogenic stage; Mvt, vitellogenic stage; Lvt, late vitellogenic stage; GVBD, germinal vesicle breakdown stage. Vertical bars represented mean $\pm \mathrm{SE}(n=3)$. Significant different letters above the vertical bars indicate difference $\left({ }^{*} P<0.05\right)$.

\subsection{Induced Expression of EsLHR mRNA by the Crab GnRH Homolog}

To further investigate whether the expression of EsLHR is regulated by GnRH, we performed in vivo injection experiment using the crab GnRH homolog. In ovary, the expression of EsLHR mRNA, in response to GnRH homolog induction, was examined by qPCR at $0 \mathrm{~h}, 6 \mathrm{~h}, 12 \mathrm{~h}, 24 \mathrm{~h}$, and $36 \mathrm{~h}$ post injection. As shown in Figure 7, the relative expression level of EsLHR in GnRH group began to rise significantly at $36 \mathrm{~h}$ post injection $(P<0.01)$, whereas no significant change in PBS-injected group and blank control group. This data indicated that GnRH homolog can induce EsLHR mRNA expression.

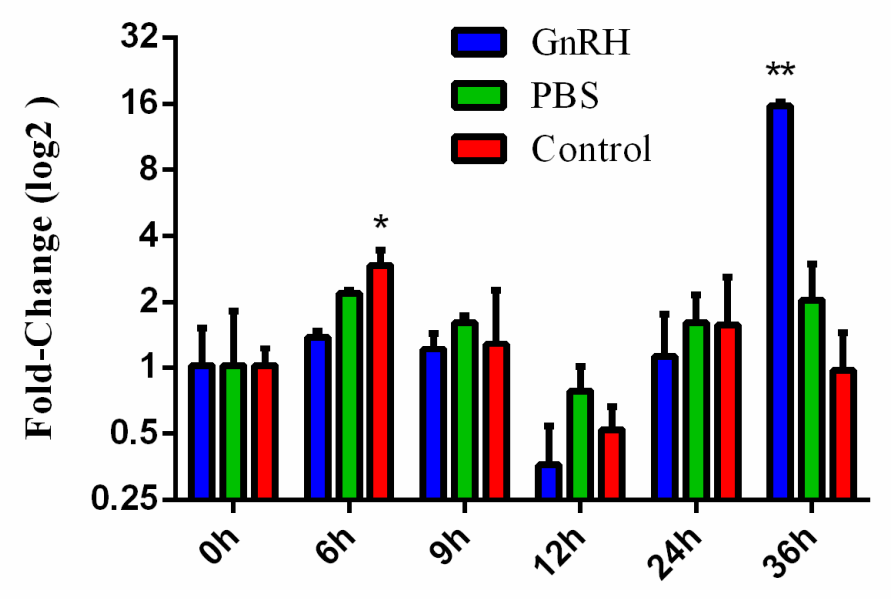

Time(h)

Figure 7. Induced expression of EsLHR mRNA by in vivo injection of the crab GnRH homolog. The blank control did not receive any treatment. The $\beta$-actin RNA was used as an internal control and the relative expression level of EsLHR was obtained relative to $\beta$-actin expression. The bars represent the mean $\pm \mathrm{SD}(n=3)$. * represents significant difference $(P<0.05)$, and ${ }^{* *}$ represents highly significant difference $(P<0.01)$. 


\section{Materials and Methods}

\subsection{Ethics Statement}

The mitten crab E. sinensis is not an endangered or protected species, and permission to perform experiments involving this species is not required in China.

\subsection{Animals and Tissue Sampling}

Adult crabs were collected from a local aquaculture farm in Chongming District, Shanghai. All the crabs were acclimated in a fresh water circulation system aquarium, supplying sufficient dissolved oxygen for recovery. At the end of seven-day feeding, various tissues, including the brain, ovary, testis, eyestalk, heart, gill, muscle, thoracic ganglion and hepatopancreas, were dissected for subsequent RNA extraction. Additionally, ovarian tissues were fixed in $4 \%$ paraformaldehyde solution overnight at $4{ }^{\circ} \mathrm{C}$ for histological observation and in situ hybridization. The developmental stages of ovaries were classified according to previously published criteria [23].

\subsection{GnRH Homolog Injection Experiments}

The individuals were divided into three groups: (1) PBS group, 25 individuals were intraperitoneal injected with $100 \mu \mathrm{L}$ PBS. (2) GnRH group, 25 individuals were intraperitoneal, injected with $100 \mu \mathrm{L}$ $\mathrm{GnRH}$ solution, at the concentration of $500 \mathrm{ng} \mathrm{GnRH/g}$ body weight (BW). (3) Blank control group, 25 individuals did not receive any treatment. Ovarian tissues from each group were sampled and frozen by liquid nitrogen in $0 \mathrm{~h}, 6 \mathrm{~h}, 9 \mathrm{~h}, 12 \mathrm{~h}, 24 \mathrm{~h}$, and $36 \mathrm{~h}$ postinjection, and the developmental state of ovarian tissues were all in late vitellogenic stage (Lvt) during the $\mathrm{GnRH}$ injection experiments.

\subsection{Cloning of the Full-Length EsLHR Complementary DNA (cDNA)}

Total RNA was extracted from the tissues using RNAiso Plus reagent (Takara, Japan), and cDNA was synthesized with SMARTer RACE (Rapid Amplification of cDNA Ends) cDNA amplification Kit (Clontech, Kusatsu, Japan) according to the manufacturer's instructions. The full-length cDNA of EsLHR was obtained by 5'-RACE and 3'-RACE with gene-specific primers (Table 1). RACE-PCR was performed in a $50 \mu \mathrm{L}$ mix containing $10 \mu \mathrm{L}$ of $5 \times$ PCR buffer, $31.75 \mu \mathrm{L}$ of PCR-grade water, $1.25 \mathrm{U}$ of Takara Ex Taq ${ }^{\circledR H S}$ (Takara), $0.5 \mu \mathrm{L}$ 5'-RACE or 3'-RACE gene-specific primer $(10 \mu \mathrm{M}), 5 \mu \mathrm{L}$ Universal Primer A Mix $(10 \times)$ and $2.5 \mu \mathrm{L}$ of RACE-Ready cDNA, under the following cycle profile: $94{ }^{\circ} \mathrm{C}$ for $30 \mathrm{~s}$ followed by 35 cycles of $94{ }^{\circ} \mathrm{C}$ for $5 \mathrm{~s}, 55^{\circ} \mathrm{C}$ for $30 \mathrm{~s}$, and $72{ }^{\circ} \mathrm{C}$ for $1 \mathrm{~min}$. The PCR products were ligated into pGEM ${ }^{\circledR}-\mathrm{T}$ Easy vector (Promega, Madison, WI, USA), transformed into competent Escherichia coli DH5 $\alpha$ cells, plated on a LB-agar Petri dish and incubated overnight at $37^{\circ} \mathrm{C}$. Positive clones containing the insert with expected size were identified by colony PCR. Eight of the positive clones were picked up and sequenced on an ABI PRISM3730 Automated Sequencer using BigDye terminator v3.1 (Applied Biosystems, Waltham, MA, USA).

Table 1. Primers used in this study.

\begin{tabular}{lll}
\hline \multicolumn{1}{c}{ Primers } & \multicolumn{1}{c}{ sequence $\left(5^{\prime} \rightarrow \mathbf{3}^{\prime}\right)$} & \multicolumn{1}{c}{ Usage } \\
\hline LHR-F1 & ATGTCCTCTGGAAGTGCAAAGAT & RT-PCR \\
LHR-R1 & TTACTGCTTGGAGAAGAAGTCTTTG & \\
LHR-F2 & GGTGGCAGGTCTTCCGCTTAT & $3^{\prime}$-RACE \\
LHR-R2 & GCCCGTCTCAGGTTTGGT & $5^{\prime}$-RACE \\
LHR-F3 & GGTGGCAGGTCTTCCGCTTAT & cloning for ISH probes \\
LHR-R3 & GCCCGTCTCAGGTTTGGTT & \\
LHR-F4 & TGGCAGGTCTTCCGCTTATT & qPCR \\
LHR-R4 & GCCCTTGTACTTCATCGCTC & \multicolumn{2}{|}{ RT-PCR and qPCR } \\
$\beta$-actin F & CCTCACCCTCAAATACCCCAT & \\
$\beta$-actin R & GGGGTGTTGAAGGTCTCGGA & \\
\hline
\end{tabular}




\subsection{Tissue Distribution of EsLHR Gene}

Various tissues were collected from three adult individuals. Total RNA from the tissues was treated with DNase I (Promega) and submitted to reverse transcription (RT). The gene-specific primers used in PCR are shown in Table 1 . The reaction conditions were $95^{\circ} \mathrm{C}$ for $5 \mathrm{~min}$, followed by 30 cycles of $94{ }^{\circ} \mathrm{C}$ for $30 \mathrm{~s}, 60{ }^{\circ} \mathrm{C}$ for $30 \mathrm{~s}, 72{ }^{\circ} \mathrm{C}$ for $1 \mathrm{~min}$. Meanwhile, $\beta$-actin was amplified as an internal control using a pair of primers (Table 1). The RT-PCR products were separated by electrophoresis on a $2.0 \%$ agarose gel and verified by sequencing.

\subsection{Probe Preparation and in situ Hybridization}

A fragment of the cDNA (393 bp) of EsLHR was cloned and ligated into pGEMT-T Easy vector (Promega), and then the recombinant plasmid was linearized with Spe I (Takara). DIG-labeled probes of anti-sense and sense were synthesized by in vitro transcription, with a DIG RNA Labeling Kit (Roche Diagnostics, Mannheim, Germany), using the SP6, and T7 RNA polymerases (Takara), respectively. The ISH of ovarian tissue was carried out as described previously [24] with minor changes. Briefly, all tissue sections $(\sim 6 \mu \mathrm{m})$ were dehydrated and deparaffinized with xylene three times, for $5 \mathrm{~min}$ each times. After rinsing, all sections were treated with $3-5 \mu \mathrm{g} \cdot \mathrm{mL}^{-1}$ proteinase $\mathrm{K}$ for $10 \mathrm{~min}$ at $37^{\circ} \mathrm{C}$. Subsequently, the slides were hybridized with DIG-labeled antisense or sense RNA probes two hours at $52{ }^{\circ} \mathrm{C}$. After serial washing, the DIG was visualized using colorimetric substrates NBT/BCIP (Roche) according to the manufacturer's instructions. For routine histological observation, the sections were stained with hematoxylin and eosin.

\subsection{Real-Time qPCR Analysis}

About 200 ng of total RNA from each sample was reverse-transcribed with iScript ${ }^{\mathrm{TM}} \mathrm{cDNA}$ Synthesis Kit (Bio-Rad, Massachusetts, CA, USA) according to the manufacturer's protocol. Melting curve analysis was performed to select the optimum primer pairs (Table 1). The resultant cDNAs were PCR-amplified in a volume of $10 \mathrm{ml}$ that consisted of RT reaction, 16 Ex Taq buffer, $0.2 \mathrm{mM}$ of each dNTP, $0.5 \mathrm{mM}$ of each primer, and 0.25 U TaKaRa Ex TaqH Hot Start Version (Takara, Tokyo, Japan). The amplification reaction procedure was performed as follows: $94{ }^{\circ} \mathrm{C}$ for $3 \mathrm{~min}$, followed by 25 cycles of $94{ }^{\circ} \mathrm{C}$ for $30 \mathrm{~s}, 57^{\circ} \mathrm{C}$ for $30 \mathrm{~s}$, and $72{ }^{\circ} \mathrm{C}$ for $1 \mathrm{~min}$. Real-time PCR was carried out using a Bio-Rad CFX96 Real-Time PCR Detection System (Bio-Rad) in a $20 \mu \mathrm{L}$ reaction mix containing $1 \mu \mathrm{L}$ cDNA template, $4 \mu \mathrm{L} 5 \times$ iScript reaction mix (Bio-Rad), $0.5 \mu \mathrm{L}$ of each primer $(10 \mu \mathrm{M})$ and $14 \mu \mathrm{L}$ nuclease-free water. The qPCR cycling conditions were as follows: $95^{\circ} \mathrm{C}$ for $30 \mathrm{~s}, 40$ cycles of $95^{\circ} \mathrm{C}$ for $5 \mathrm{~s}$ and $60^{\circ} \mathrm{C}$ for $30 \mathrm{~s}$, followed by dissociation curve analysis at $95^{\circ} \mathrm{C}$ for $15 \mathrm{~s}, 60^{\circ} \mathrm{C}$ for $1 \mathrm{~min}$ and $95^{\circ} \mathrm{C}$ for $15 \mathrm{~s}$ to verify the amplification of a single product. A reaction without cDNA was used as the negative control. The housekeeping gene $\beta$-actin was amplified as an internal reference. The expression levels were calculated using the $2^{-\triangle \triangle C T}$ method [25]. Each sample was run in triplicate. The relative expression of fold change was measured by the ratio of the target gene to that of internal reference gene within the same sample after $\log 2$ transformation. Data were presented as the mean \pm standard error (SE). The mean difference was determined by one-way ANOVA analysis followed by $t$ test or multiple range $t$ test using SPSS statistical software (version 20.0) and a $P$ value $<0.05$ was considered to be significantly different.

\subsection{Bioinformatics Analysis}

Nucleotide and amino acid sequences were identified using the BLAST program (http:/ / blast.ncbi. nlm.nih.gov/Blast.cgi). The open reading frame (ORF) of EsLHR was determined by the ORF Finder (http://www.ncbi.nlm.nih.gov/projects/gorf/). The cleavage site for the putative signal peptide was predicted using online website (TMPRED, https:/ / embnet.vital-it.ch/software/TMPRED_form.html). The deduced amino acid sequences of EsLHR were aligned with the amino acid sequence of LHRs, and related GPCRs, using the ClustalW program (ClustalW2, EMBL, Heidelberg, Germany). 
The representative sequences of EsLHR homolog were obtained from the GenBank database for phylogenetic analysis. A phylogenetic tree was constructed based on the deduced full-length amino acid sequence alignments by the Neighbor-Joining (NJ) algorithm method embedded in the MEGA software 5.0 (Aubencheul-au-bac, France). The bootstrap test was employed based on 10,000 pseudo-replications to assess the reliability of the phylogenetic tree.

\section{Discussion}

To the best of our knowledge, this study represents the first report on the identification of a $L H R$ gene in decapods crustacean. The mitten crab EsLHR, encoding a protein, contained typical features of the known glycoprotein receptor LHR, including ECD, TMD, and ICD (Figure 1). Seven exons were detected in EsLHR genomic sequence. The seven-TMDs of EsLHR were coded by four exons, which is most similar to the wheat stem sawfly Cehus cinctus (Figure 2). In invertebrates, the genomic structures of $L H R$ genes were quite different among species. For example, seven-TMDs were encoded by one exon in the horseshoe crab Limulus polyphemus and the scorpion Centryroides sculpturatus, whereas the TMDs were encoded with the last two exons in the flour beetle Tribolium castaneum. However, the genomic sequences of most vertebrates LHRs gene contain 11 exons, in which the last exon encodes for TMDs (Figure 2) [26]. These data indicated that the genomic structure of LHR gene was not fully conserved between the invertebrates and vertebrates, and the multiple exons, coding the transmembrane domains, could represent an ancestral LHR form.

As an important signal transduction receptor for regulating gonad development, LHR mRNA was detected at the highest level in gonad of many fish species, such as the yellow catfish (Pelteobagrus fulvidraco), goldfish (Lubricogobius exiguus), mummichog (Fundulus heteroclitus) and sea bass (Dicentrarchus labrax) [12,27-29]. But, in African catfish (Clarias gariepinus) and Cynoglossus semilaevis $[19,30]$, the expression of $L H R$ was not the highest in the gonads. Our tissue expression studies revealed that EsLHR were expressed at the highest level in the ovary, suggesting an essential role for EsLHR in the reproduction of E. sinensis. It is has demonstrated that LH, coupled with its receptor LHR, plays a key role in controlling ovarian development in fish, especially in the final oocyte maturation. Generally, the LH-mediated control of ovarian maturation requires the timely and quantitative expression of the LHR in the ovary. [31,32]. Hence, we investigated the expression profiles of crab EsLHR during ovarian development. The qPCR result showed that EsLHR abundances in Lvt and GVBD were significantly higher than in Evt and Mvt stages (Figure 6). Similarly, a higher expression of the LHR mRNA was detected in a late stage of follicular development in bovine [33]. In zebrafish, the expression of $L H R$ was hardly detected in the immature ovary, but initiated at the beginning of vitellogenesis and reached peak level at the full-grown oocyte stage [11]. These results indicated that, like vertebrate $L H R, E s L H R$ may have implications in the final meiotic maturation of oocytes in E. sinensis. In additional, a higher expression of EsLHR mRNA was also detected in Pvt. This result was supported by subsequent ISH analysis. Strong mRNA hybrid-signal was mainly visualized in the ooplasm of Pvt oocytes (Figure 5B), suggesting that EsLHR could also have a potential role in Pvt stage besides in the final oocyte maturation. However, ISH analysis showed that the hybridization signal was undetectable in oocytes at Lvt and GVBD stages (Figure $5 \mathrm{~N}$ ). The inconsistent results between ISH and qPCR were also achieved in the characterization of other function genes $[5,22,34]$. The paradoxical for those data may result from the large amounts of yolk granules in the fully-grown oocyte at Lvt, which could inhibit probes from binding their target transcripts in ISH analysis. Also, the enlargement of oocytes seem to dilute the concentration of EsLHR mRNA [35].

In vertebrates, the synthesis and release of LH is stimulated by GnRH and gonad maturation is mediated via GnRH signaling pathway [36]. In decapod species, GnRH-like peptide of crab Portunus pelagicus was detected by using anti-GnRH antibody $[37,38]$ and $\mathrm{GnRH}$ analogue can promote the ovarian maturation and spawning in giant freshwater prawn, Macrobrachium rosenbergii [39]. LH immune-signal was also detected in the brain of the mud crab Scylla serrate and the swimming crab Portunus trituberculatus by vertebrate LH antiserum [40,41]. In vivo injection of ovine LH can 
stimulating ovaries maturation of the sand shrimp Crangon, crangon [42]. In our previous study, a gonadotropin-releasing hormone $(\mathrm{GnRH})$-like peptide was partially isolated from the brain extract of Chinese mitten crab E. sinensis [43]. Synthesized the crab GnRH homolog peptide can induce GVBD of oocyte [44]. GnRH receptor (GnRHR) homolog was cloned and its corresponding GnRH signal pathway was revealed by transcriptomic analysis [22]. To investigate whether the crab EsLHR is involved in the GnRH signaling pathway, the expression of EsLHR mRNA was investigated by in vivo injection of the crab GnRH homolog. The relative expression level of EsLHR mRNA increased significantly at $36 \mathrm{~h}$ post injection (Figure 7), strongly suggesting that the expression EsLHR is regulated by GnRH homolg.

In conclusion, this study presents the first report of the cloning and characterization of the EsLHR gene in E. sinensis. Significantly, the high expression of EsLHR in the ovaries at Pvt, Lvt, and GVBD stage suggested that EsLHR could have implications in both early ovarian development and the final meiotic maturation of GVBD oocytes. The crab GnRH homolog can induced EsLHR expression, indicating that EsLHR is involved in regulation of oocyte maturation through GnRH signaling pathway.

Author Contributions: L.-J.Y. collected samples and conducted laboratory work. C.P. and B.-H.L. analyzed the data and wrote the manuscript. J.-B.F. performed bioinformatics analysis on the EsLHR genomic sequence. G.-F.Q. conceived the study and contributed to improving the final manuscript. All authors approved the final manuscript.

Funding: This work was supported by the Natural Science Foundation of China (project number 41476130).

Acknowledgments: We would like to thank Miss Xue Liu for the assistance with the statistical analysis and the two anonymous reviewers for their valuable comments to the manuscript.

Conflicts of Interest: The authors declare no conflict of interest.

\section{References}

1. Kalra, S.P. Neural Regulation of Luteinizing Hormone Secretion in the Rat*. Endocr. Rev. 1983, 4, 311-351. [CrossRef]

2. Sower, S.A.; Freamat, M.; Kavanaugh, S.I. The origins of the vertebrate hypothalamic-pituitary-gonadal (HPG) and hypothalamic-pituitary-thyroid (HPT) endocrine systems: New insights from lampreys. Gen. Comp. Endocrinol. 2009, 161, 20-29. [CrossRef]

3. Schulz, R.; Vischer, H.; Cavaco, J.E.; Santos, E.; Tyler, C.; Goos, H.; Bogerd, J. Gonadotropins, their receptors, and the regulation of testicular functions in fish. Comp. Biochem. Physiol. B Biochem. Mol. Boil. 2001, 129, 407-417. [CrossRef]

4. Levavi-Sivan, B.; Bogerd, J.; Mañanós, E.; Gómez, A.; Lareyre, J.; Mañanós, E. Perspectives on fish gonadotropins and their receptors. Gen. Comp. Endocrinol. 2010, 165, 412-437. [CrossRef] [PubMed]

5. Du, Y.-X.; Ma, K.-Y.; Qiu, G.-F. Discovery of the genes in putative GnRH signaling pathway with focus on characterization of GnRH-like receptor transcripts in the brain and ovary of the oriental river prawn Macrobrachium nipponense. Aquaculture 2015, 442, 1-11. [CrossRef]

6. Zhang, Y.; Devries, M.E.; Skolnick, J.; Murray, D. Structure Modeling of All Identified G Protein-Coupled Receptors in the Human Genome. PLOS Comput. Boil. 2006, 2, e13.

7. Rispoli, L.; Nett, T. Pituitary gonadotropin-releasing hormone (GnRH) receptor: Structure, distribution and regulation of expression. Anim. Reprod. Sci. 2005, 88, 57-74. [CrossRef]

8. Hauze, D.B.; Chengalvala, M.V.; Cottom, J.E.; Feingold, I.B.; Garrick, L.; Green, D.M.; Huselton, C.; Kao, W.; Kees, K.; Lundquist, J.T.; et al. Small molecule antagonists of the gonadotropin-releasing hormone $(\mathrm{GnRH})$ receptor: Structure-activity relationships of small heterocyclic groups appended to the 2-phenyl-4-piperazinyl-benzimidazole template. Bioorganic Med. Chem. Lett. 2009, 19, 1986-1990. [CrossRef]

9. Kumar, R.; Trant, J.M. Piscine glycoprotein hormone (gonadotropin and thyrotropin) receptors: A review of recent developments. Comp. Biochem. Physiol. B Biochem. Mol. Boil. 2001, 129, 347-355. [CrossRef]

10. Oba, Y.; Hirai, T.; Yoshiura, Y.; Kobayashi, T.; Nagahama, Y. Fish gonadotropin and thyrotropin receptors: The evolution of glycoprotein hormone receptors in vertebrates. Comp. Biochem. Physiol. B Biochem. Mol. Boil. 2001, 129, 441-448. [CrossRef] 
11. Kwok, H.-F.; So, W.-K.; Wang, Y.; Ge, W. Zebrafish Gonadotropins and Their Receptors: I. Cloning and Characterization of Zebrafish Follicle-Stimulating Hormone and Luteinizing Hormone Receptors-Evidence for Their Distinct Functions in Follicle Development1. Boil. Reprod. 2005, 72, 1370-1381. [CrossRef]

12. Rocha, A.; Gómez, A.; Zanuy, S.; Cerdá-Reverter, J.M.; Carrillo, M. Molecular characterization of two sea bass gonadotropin receptors: cDNA cloning, expression analysis, and functional activity. Mol. Cell. Endocrinol. 2007, 272, 63-76. [CrossRef]

13. An, K.W.; Lee, K.-Y.; Yun, S.G.; Choi, C.Y. Molecular characterization of gonadotropin subunits and gonadotropin receptors in black porgy, Acanthopagrus schlegeli: Effects of estradiol-17 $\beta$ on mRNA expression profiles. Comp. Biochem. Physiol. B Biochem. Mol. Boil. 2009, 152, 177-188. [CrossRef]

14. Kobayashi, T.; Pakarinen, P.; Torgersen, J.; Huhtaniemi, I.; Andersen, Ø. The gonadotropin receptors FSH-R and LH-R of Atlantic halibut (Hippoglossus hippoglossus)-2. Differential follicle expression and asynchronous oogenesis. Gen. Comp. Endocrinol. 2008, 156, 595-602. [CrossRef]

15. Oba, Y.; Hirai, T.; Yoshiura, Y.; Yoshikuni, M.; Kawauchi, H.; Nagahama, Y. Cloning, Functional Characterization, and Expression of a Gonadotropin Receptor cDNA in the Ovary and Testis of Amago Salmon (Oncorhynchus rhodurus). Biochem. Biophys. Res. Commun. 1999, 263, 584-590. [CrossRef]

16. Maugars, G.; Schmitz, M. Molecular cloning and characterization of FSH and LH receptors in Atlantic salmon (Salmo salar L.). Gen. Comp. Endocrinol. 2006, 149, 108-117. [CrossRef]

17. Mittelholzer, C.; Andersson, E.; Taranger, G.; Consten, D.; Hirai, T.; Senthilkumaran, B.; Nagahama, Y.; Norberg, B. Molecular characterization and quantification of the gonadotropin receptors FSH-R and LH-R from Atlantic cod (Gadus morhua). Gen. Comp. Endocrinol. 2009, 160, 47-58. [CrossRef]

18. Jeng, S.-R.; Yueh, W.-S.; Chen, G.-R.; Lee, Y.-H.; Dufour, S.; Chang, C.-F. Differential expression and regulation of gonadotropins and their receptors in the Japanese eel, Anguilla japonica. Gen. Comp. Endocrinol. 2007, 154, 161-173. [CrossRef]

19. Vischer, H.; Bogerd, J. Cloning and Functional Characterization of a Gonadal Luteinizing Hormone Receptor Complementary DNA from the African Catfish (Clarias gariepinus). Boil. Reprod. 2003, 68, 262-271. [CrossRef]

20. Kumar, R.S.; Ijiri, S.; Trant, J.M. Molecular Biology of Channel Catfish Gonadotropin Receptors: 1. Cloning of a Functional Luteinizing Hormone Receptor and Preovulatory Induction of Gene Expression1. Boil. Reprod. 2001, 64, 1010-1018. [CrossRef]

21. Liu, X.; Ma, K.; Liu, Z.; Feng, J.; Ye, B.; Qiu, G. Transcriptome analysis of the brain of the Chinese mitten crab, Eriocheir sinensis, for neuropeptide abundance profiles during ovarian development. Anim. Reprod. Sci. 2019, 201, 63-70. [CrossRef]

22. Ma, K.-Y.; Zhang, S.-F.; Wang, S.-S.; Qiu, G.-F. Molecular cloning and characterization of a gonadotropinreleasing hormone receptor homolog in the Chinese mitten crab, Eriocheir sinensis. Gene 2018, 665, 111-118. [CrossRef]

23. Fang, J.-J.; Qiu, G.-F. Molecular cloning of cyclin B transcript with an unusually long $3^{\prime}$ untranslation region and its expression analysis during oogenesis in the Chinese mitten crab, Eriocheir sinensis. Mol. Biol. Rep. 2009, 36, 1521-1529. [CrossRef]

24. Ma, K.-Y.; Chen, J.; Liu, Z.-Q.; Qiu, G.-F. Inhibitory effects of RNAi-mediated knockdown of EsDmrt-like gene on testicular development in the Chinese mitten crab Eriocheir sinensis. Aquaculture 2016, 463, 217-223. [CrossRef]

25. Livak, K.J.; Schmittgen, T.D. Analysis of Relative Gene Expression Data Using Real-Time Quantitative PCR and the 2- $\Delta \Delta \mathrm{CT}$ Method. Methods 2001, 25, 402-408. [CrossRef]

26. Bogerd, J.; Granneman, J.C.; Schulz, R.W.; Vischer, H.F. Fish FSH receptors bind LH: How to make the human FSH receptor to be more fishy? Gen. Comp. Endocrinol. 2005, 142, 34-43. [CrossRef]

27. Kobayashi, Y.; Nakamura, M.; Sunobe, T.; Usami, T.; Kobayashi, T.; Manabe, H.; Paul-Prasanth, B.; Suzuki, N.; Nagahama, Y. Sex Change in the Gobiid Fish Is Mediated through Rapid Switching of Gonadotropin Receptors from Ovarian to Testicular Portion or Vice Versa. Endocrinology 2009, 150, 1503-1511. [CrossRef]

28. Ohkubo, M.; Yabu, T.; Yamashita, M.; Shimizu, A. Molecular cloning of two gonadotropin receptors in mummichog Fundulus heteroclitus and their gene expression during follicular development and maturation. Gen. Comp. Endocrinol. 2013, 184, 75-86. [CrossRef]

29. Nyuji, M.; Kazeto, Y.; Izumida, D.; Tani, K.; Suzuki, H.; Hamada, K.; Mekuchi, M.; Gen, K.; Soyano, K.; Okuzawa, K. Greater amberjack Fsh, Lh, and their receptors: Plasma and mRNA profiles during ovarian development. Gen. Comp. Endocrinol. 2016, 225, 224-234. [CrossRef] 
30. Chen, J.; Liu, P.; Li, Z.; Chen, Y.; Qiu, G.-F. The cloning of the cdk2 transcript and the localization of its expression during gametogenesis in the freshwater giant prawn, Macrobrachium rosenbergii. Mol. Boil. Rep. 2013, 40, 4781-4790. [CrossRef]

31. Nagahama, Y.; Yoshikuni, M.; Yamashita, M.; Tokumoto, T.; Katsu, Y. 4 Regulation of Oocyte Growth and Maturation in Fish. In Current Topics in Developmental Biology; Pedersen, R.A., Schatten, G.P., Eds.; Academic Press: Cambridge, MA, USA, 1995; pp. 103-145.

32. Swanson, P. Pituitary gonadotropins and their receptors in fish. In Proceedings of the XIII International Congress of Comparative Endocrinology, Yokohama, Japan, 16-21 November 1997; pp. 841-846.

33. Bao, B.; Garverick, H.A.; Smith, G.W.; Smith, M.F.; Salfen, B.E.; Youngquist, R.S. Changes in Messenger Ribonucleic Acid Encoding Luteinizing Hormone Receptor, Cytochrome P450-Side Chain Cleavage, and Aromatase are Associated with Recruitment and Selection of Bovine Ovarian Follicles1. Boil. Reprod. 1997, 56, 1158-1168. [CrossRef]

34. Qiu, G.-F.; Chen, Y.; Cui, Z.; Zhu, X.-L. Localization of germline marker vasa homolog RNA to a single blastomere at early cleavage stages in the oriental river prawn Macrobrachium nipponense: Evidence for germ cell specification by preformation. Gene 2013, 513, 53-62. [CrossRef]

35. Chen, X.Y.; Wen, H.S.; Feng, H.E.; Chen, C.F.; Zhang, J.R.; Jin, G.X.; Shi, B. Partial Sequence Cloning of LHR Gene in Cynoglossus semilaevis and Its Tissue Expression Analysis. Period. Ocean Univ. China 2010, 40, 71-77.

36. Herbison, A.E. Multimodal Influence of Estrogen upon Gonadotropin-Releasing Hormone Neurons. Endocr. Rev. 1998, 19, 302-330. [CrossRef]

37. Saetan, J.; Senarai, T.; Tamtin, M.; Weerachatyanukul, W.; Chavadej, J.; Hanna, P.J.; Parhar, I.; Sobhon, P.; Sretarugsa, P. Histological organization of the central nervous system and distribution of a gonadotropin-releasing hormone-like peptide in the blue crab, Portunus pelagicus. Cell Res. 2013, 353, 493-510. [CrossRef]

38. Senarai, T.; Saetan, J.; Tamtin, M.; Weerachatyanukul, W.; Sobhon, P.; Sretarugsa, P. Presence of gonadotropin-releasing hormone-like peptide in the central nervous system and reproductive organs of the male blue swimming crab, Portunus pelagicus, and its effect on spermatogenesis. Cell Res. 2016, 365, 265-277. [CrossRef]

39. Ngernsoungnern, P.; Ngernsoungnern, A.; Sobhon, P.; Sretarugsa, P. Gonadotropin-releasing hormone $(\mathrm{GnRH})$ and a GnRH analog induce ovarian maturation in the giant freshwater prawn, Macrobrachium rosenbergii. Invertebr. Reprod. Dev. 2009, 53, 125-135. [CrossRef]

40. Ye, H.-H.; Huang, H.Y.; Li, S.-J.; Wang, G.Z. Immunorecognition of FSH and LH in Optic Ganglion of Scylla serrata. J. Xiamen Univ. 2006, 45, 297-298.

41. Huang, H.; Ye, H.; Li, S.; Wang, G. Immunocytological evidence for the presence of vertebrate FSH- and LH-like substances in the brain and thoracic ganglion of the swimming crab, Portunus trituberculatus. Prog. Nat. Sci. Mater. Int. 2008, 18, 1453-1457. [CrossRef]

42. Zukowska-Arendarczyk, M. Effect of hypophyseal gonadotropins (FSH and LH) on the ovaries of the sand shrimp Crangon crangon (Crustacea: Decapoda). Mar. Boil. 1981, 63, 241-247. [CrossRef]

43. Wang, C.-Z.; Qiu, G.-F. Partial isolation and immunological characterization of a GnRH-like peptide from Chinese mitten crab (Eriocheir sinensis). J. Fish. 2012, 36, 908. [CrossRef]

44. Song, Y.-N.; Shi, L.-L.; Liu, Z.-Q.; Qiu, G.-F. Global analysis of the ovarian microRNA transcriptome: Implication for miR-2 and miR-133 regulation of oocyte meiosis in the Chinese mitten crab, Eriocheir sinensis (Crustacea:Decapoda). BMC Genom. 2014, 15, 547. [CrossRef]

(C) 2019 by the authors. Licensee MDPI, Basel, Switzerland. This article is an open access article distributed under the terms and conditions of the Creative Commons Attribution (CC BY) license (http://creativecommons.org/licenses/by/4.0/). 